\title{
BMJ Open The current health of the signing Deaf community in the UK compared with the general population: a cross-sectional study
}

\author{
Alan Emond, ${ }^{1}$ Matthew Ridd, ${ }^{1}$ Hilary Sutherland, ${ }^{2}$ Lorna Allsop, ${ }^{2}$ \\ Andrew Alexander, ${ }^{3} \mathrm{Jim} \mathrm{Kyle}{ }^{4}$
}

To cite: Emond A, Ridd M, Sutherland $\mathrm{H}$, et al. The current health of the signing Deaf community in the UK compared with the general population:

a cross-sectional study. BMJ Open 2015;5:e006668. doi:10.1136/bmjopen-2014006668

- Prepublication history for this paper is available online. To view these files please visit the journal online (http://dx.doi.org/10.1136/ bmjopen-2014-006668).

Received 17 September 2014 Revised 28 November 2014 Accepted 30 December 2014

CrossMark

For numbered affiliations see end of article.

Correspondence to Professor Alan Emond, alan.emond@bristol.ac.uk

\section{ABSTRACT}

Objectives: To assess the current health of the Deaf community in the UK and compare with the general population.

Design: A quota sample of adult Deaf British Sign Language (BSL) users underwent a health assessment and interview in 2012-2013. Comparative data were obtained from the Health Survey for England (HSE) 2011 and the Quality Outcomes Framework (QOF) 2012.

Setting: Participants completed a structured interview and health assessment at seven Bupa centres across the UK, supported in BSL by Deaf advisers and interpreters.

Participants: 298 Deaf people, 20-82 years old, 47\% male, with $12 \%$ from ethnic minorities.

Main outcome measures: Self-reported health conditions, medication usage, tobacco and alcohol consumption; measured blood pressure (BP), body mass index, fasting blood sugar and lipid profile.

Results: Rates of obesity in the Deaf sample were high, especially in those over 65 years, and $48 \%$ were in a high risk group for serious illness. High BP readings were obtained in $37 \%$ of Deaf people $(21 \%$ in HSE): $29 \%$ were unaware of this ( $6 \%$ in HSE). Only $42 \%$ of Deaf people being treated for hypertension had adequate control, compared with $62 \%$ of the general population. Deaf people with self-reported cardiovascular disease (CVD) were significantly less than the general population. One-third of Deaf participants had total cholesterol $>5 \mathrm{mmol} / \mathrm{L}$ but although control rates were high compared with HSE, treatment rates for self-reported CVD were half the general population rate. Eleven per cent of Deaf participants had blood sugar at prediabetic or diabetic levels, and $77 \%$ of those at prediabetic levels were unaware of it. Deaf respondents self-reported more depression (31\% of women, $14 \%$ of men), but less smoking (8\%) and alcohol intake (2-8 units/week).

Conclusions: Deaf people's health is poorer than that of the general population, with probable underdiagnosis and undertreatment of chronic conditions putting them at risk of preventable ill health.

\section{Strengths and limitations of this study}

- This is the first comprehensive survey of the health of Deaf adults in the UK, utilising British Sign Language.

- Mixed methods were used to obtain a standardised health assessment on all participants, including questionnaire and interview data, and a structured medical assessment undertaken by an independent provider (Bupa Healthcare).

- Data were usually self-reported for the medical history and medication usage, without access to individuals' health records.

- The 'well person' medical assessment offered by Bupa was a single check on 1 day and did not include any information from the individual's existing medical record.

- The data sets that were used to provide comparisons with the hearing population (the Health Survey for England and the Quality Outcome Framework) were derived only from England and have their own limitations.

\section{INTRODUCTION}

Deaf adults in the UK occupy poorer socioeconomic positions, have poorer literacy and have limited access to communicate through speech. Yet they have their own fully functioning language (British Sign LanguageBSL), their own community network, and a rich and vibrant culture. ${ }^{1}$ We use Deaf (with a capital D as in English, French) to indicate membership of the sign language using community.

The UK Census $2011^{2}$ for England and Wales recorded the use of BSL as the main language for 15487 people. Given the difficulties of Deaf people completing the form and the fact that the Census obtained only 94\% returns, we estimate that potentially 20000 people are Deaf community members and using BSL. There may be other users of BSL who are bilingual. Although these 
represent very small numbers of Deaf patients in any one general practitioner (GP) practice, they are important because of the enormous difficulties experienced by Deaf people in accessing healthcare and in communicating with clinicians in consultations. Although there is evidence $^{3-5}$ that Deaf people have poor access to healthcare, there are few data in the UK or worldwide concerning their health status. ${ }^{6}$ The claimed prevalence of mental health problems, such as anxiety and depression, in Deaf people is greater than that of the general population. ${ }^{7}$ The extent of physical health problems and chronic disease in the Deaf community in the UK is not known.

The aim of the Deaf Health study was to assess the current health of a representative sample of the Deaf community in the UK and to compare with that of the general population.

\section{METHODS}

Sample

As no register of Deaf people exists, it was not possible to recruit a random sample of the UK Deaf community. Instead, a quota sample of adults was planned, stratified by age and gender, and ethnicity to match the UK population, and to represent the main populated areas. Recruitment of BSL-using Deaf adults to this quota sample was undertaken (1) by approaching respondents who had given consent to be contacted in a previous online survey of Deaf people carried out by Ipsos MORI for SignHealth ${ }^{8}$ $(n=80)$, and (2) by direct contact with the Deaf community via Deaf clubs and networks $(n=223)$.

Information in BSL about the study was made available in video online and informed consent to participate was obtained in BSL and English. A total of 298 participants, aged from 20 to 82 years, was made up of 139 men and 159 women, with $11 \%$ from ethnic minorities and attended for free health assessments during 2012 and 2013 at Bupa centres in Bristol, London, Brighton, Solihull, Cardiff, Manchester and Glasgow. In each session, they were supported in BSL by Deaf advisers and interpreters.

\section{Measures}

The $1 \mathrm{~h}$ structured health assessment consisted of the standard health check provided by Bupa Healthcare, augmented by a set of health questions based on the Health Survey for England (HSE). The assessment started with a fasting blood test-following an overnight fast for a morning appointment and a $6 \mathrm{~h}$ fast for an afternoon appointment. After a light snack and a drink, participants were weighed with light clothing and no shoes, and their height measured using a standing stadiometer. Body mass index $(\mathrm{BMI})\left(\mathrm{wt} / \mathrm{ht}^{2}\right)$ was then calculated. Body fat percentage was measured using bioelectrical impedance (Bodystat 1500). Blood pressure (BP) was measured in the resting state, sitting, using an electronic sphygmomanometer (Omron). At least two BP measurements were taken, with the lowest reading recorded and checked using an aneroid sphygmomanometer, if necessary.
A structured interview in two parts: (1) with a Bupa health adviser supported by a BSL interpreter, and (2) directly with a Deaf adviser, using BSL, then explored the participant's medical history, their awareness of any current health conditions, their current medication usage and consumption of cigarettes and alcohol. Following the assessment, the results were provided in a written report to the Deaf participant, with an explanation given by the Bupa adviser and interpreted in BSL, together with guidance on what action to take about the results, including showing the results to their GP.

Resting BP of the participants was classified using the BHS guidelines 2004: low-normal (systolic <120: diastolic $<80)$; high normal (120-139; 80-89), mild hypertension (140-159; 90-99) and moderate-severe hypertension $(160+; 100+)$. Consistent with the definition was used in the HSE 2011 for doctor-diagnosed cardiovascular disease (CVD), we defined the presence of CVD as the self-report of any one or more of the following: angina, heart failure, heart attack, stroke and atrial fibrillation. For fasting blood sugar, we used the accepted classification of less than $6.1 \mathrm{mmol} / \mathrm{L}$ as normal, $6.1-7.0 \mathrm{mmol} / \mathrm{L}$ as prediabetic and 7.1 or more as diabetic.

\section{Analysis}

Comparative data for the hearing population were derived from the HSE 2009, 2010 and 2011, ${ }^{9}$ and the Quality and Outcomes Framework (QOF) $2012{ }^{10}$ for all GP surgeries in England. Initial analysis was descriptive and where appropriate comparisons could be made between the Deaf sample and the general population, simple statistical comparisons were carried out using $\chi^{2}$ tests.

\section{RESULTS}

\section{Sample}

The final recruited sample (table 1) was close to the designed sampling frame, although young adults aged 18-24 years were under-represented. There is a slight

\begin{tabular}{lcc}
$\begin{array}{l}\text { Table } 1 \\
\text { ethnicity }\end{array}$ & The Deaf Health sample, by age, gender and \\
\hline \multicolumn{4}{c}{$\begin{array}{l}\text { Study sample, } \\
\text { number (\%) }\end{array}$} & $\begin{array}{c}\text { Target number by } \\
\text { UK census (\%) }\end{array}$ \\
\hline Age (years) & & \\
$18-24$ & $8(3)$ & $36(12)$ \\
$25-44$ & $113(38)$ & $105(35)$ \\
$45-64$ & $122(41)$ & $96(32)$ \\
$65-82$ & $55(18)$ & $63(21)$ \\
Gender & $139(47)$ & $150(50)$ \\
Male & $159(53)$ & $150(50)$ \\
Female & & \\
Ethnicity & $261(88)$ & $36(12)$ \\
White & $35(12)$ & \\
Black and & & \\
minority ethnic & & \\
groups & &
\end{tabular}


imbalance of women among the Deaf participants and this is most marked proportionately in the middle-aged group (too many) and in the elderly group (too few). These variations are similarly found in the other major comparator data sets.

The UK regions and countries of residence of the participants were London and South England (34\%), West of England and Wales (21\%), Midlands (19\%), North England (14\%) and Scotland (12\%).

\section{Obesity}

Overall, $41 \%$ of the Deaf participants were overweight (BMI 25-30), and $30 \%$ were clinically obese (BMI $>30)$. The gender difference seen in the general population was not observed in the Deaf sample. In the HSE data set, $65 \%$ of men and $58 \%$ of women were overweight or obese while the corresponding figures for Deaf participants were $72 \%$ and $71 \%$. $\left(\mathrm{X}^{2}=23.5, \mathrm{df}=2, \mathrm{p}<0.001\right)$. In the Deaf sample, $90 \%$ of those over 65 years were classed as overweight or obese.

Mean waist circumference for Deaf men was $97.9 \mathrm{~cm}$ (SE 1.1) and for Deaf women was $92.6 \mathrm{~cm}$ (SE 1.1). This compares to 97.1 (SE 0.38) and $88.5 \mathrm{~cm}$ (SE 0.38) for the general population (HSE 2011). The frequency of raised waist circumference for Deaf males and females was $57 \%$ and $76 \%$, respectively, as compared to $34 \%$ and $47 \%$ from the HSE (comparison for males: $X^{2}=9.7, \mathrm{df}=1$, $\mathrm{p}<0.01$; for females: $\mathrm{X}^{2}=47.6, \mathrm{df}=1, \mathrm{p}<0.001$ ).

The waist circumference and BMI data were combined to give a categorisation of risk of serious illness (coronary heart disease, type 2 diabetes, osteoarthritis and some cancers) using National Institute for Health and Care Excellence (NICE) 2006 predictions. ${ }^{11}$ At least $48 \%$ of Deaf people would be placed in the 'high to very high risk' category as a result of their BMI and waist circumference measurements (table 2).

\section{Blood pressure}

The frequency of raised BP was higher in the Deaf participants $(37 \%)$ than that reported in the HSE (21\%) $\left(\mathrm{X}^{2}=6.9, \mathrm{df}=1, \mathrm{p}<0.01\right)$ (table 3$)$. Moderate-severely high $\mathrm{BP}$ was significantly more common in Deaf men $(15.9 \%)$ than in Deaf women $(7.7 \%)\left(\mathrm{X}^{2}=18.1, \mathrm{df}=3, \mathrm{p}<0.001\right)$.
Table 3 Comparison (\%) of raised BP, by gender (Deaf $n=287$; HSE $n=4753$ )

\begin{tabular}{lll}
\hline & \multicolumn{2}{l}{ Measured BP $>$ 140/90 } \\
\cline { 2 - 3 } & Deaf & HSE 2011 \\
\hline Males & 41.7 & 20.0 \\
Females & 32.2 & 17.0 \\
Overall & 36.6 & 21.1 \\
\hline
\end{tabular}

$\mathrm{BP}$, blood pressure; HSE, Health Survey for England.

The awareness of their raised BP was poor in the Deaf sample, with 68 (23\%) self-reporting they had hypertension. Of those who self-reported they did not have a problem of high BP, 29\% had raised clinic BP readings. Only half of those with moderate-severely raised BP levels were aware they had a problem.

In the general population, HSE 2009 reported that $6 \%$ were not aware of their raised BP (29\% had surveydiagnosed raised BP and 23\% self-reported hypertension). The comparative figures in this study for Deaf people are $14 \%$ unaware $(37 \%$ had measured raised BP and $23 \%$ self-reported hypertension).

The detection rates of hypertension in the general population aged 18-80 years, calculated from data reported in HSE 2011, were 58\% (male) and 59\% (female). The corresponding figures for Deaf people were $44 \%$ (male) and 54\% (female). There was evidence of a difference between Deaf males and men in the general population $\left(X^{2}=5.16, d f=1, p<0.05\right)$.

Of the 68 Deaf people who reported they did have hypertension, only $51 \%$ were receiving antihypertensive medication ( $\beta$ blockers, ACE inhibitors, calcium channel blockers, angiotensin II receptor blockers or diuretics). Among those Deaf people apparently receiving treatment for hypertension, only $42 \%$ had measurements of 140/90 or less. This contrasts with the HSE $2011(<140 /$ $90)$ report of $62 \%$ and QOF 2012 figures $(\leq 150 / 90)$ of $80 \%$ with adequate control.

\section{Cardiovascular Disease}

Self-report of CVD was significantly less among Deaf people than in the general population $\left(\mathrm{X}^{2}=7.8, \mathrm{df}=1\right.$, $\mathrm{p}<0.01)$ but with higher rates of self-report among Deaf

Table 2 Risk of illness estimates from BMI and waist circumference (risk adapted from the NICE, $2006^{11}$ predictions). Per cent of the Deaf sample in each risk category $(n=288)$.

\begin{tabular}{llll}
\hline BMI & Normal waist circumference & High waist circumference & Very high waist circumference \\
\hline Desirable & $23 \%$ & $6 \%$ & $1 \%$ \\
$20-25$ & No increased risk & No increased risk & Increased risk \\
Overweight & $9 \%$ & $13 \%$ & $18 \%$ \\
$26-30$ & No increased risk & Increased risk & High risk \\
Moderate obesity & $1 \%$ & $2 \%$ & $26 \%$ \\
$31-40$ & Increased to very high risk & High to very high risk & very high risk \\
Severe obesity & & & $2 \%$ \\
$41+$ & & & Very high risk \\
\hline BMI, body mass index; NICE, National Institute for Health and Care Excellence. &
\end{tabular}


women. The association of increasing prevalence with age was not as strong as in the general population (table 4).

Of those who said they did have CVD, only $45 \%$ were taking aspirin or clopidogrel. A comparison with HSE 2011 is limited, as younger people are excluded and the data for women are treated as unreliable. For men, aged 55-84 years in HSE, the treatment rate for ischaemic heart disease and stroke was between $61 \%$ and $70 \%$; in comparison, for Deaf men aged 45-84 years, the treatment rate for all CVD was $45 \%$.

\section{Cholesterol}

The mean level of cholesterol in male and female Deaf participants $(4.6 \mathrm{mmol} / \mathrm{L}$ and $4.5 \mathrm{mmol} / \mathrm{L}$, respectively) was lower than reported in the HSE $(5.1 \mathrm{mmol} / \mathrm{L}$ and $5.2 \mathrm{mmol} / \mathrm{L}$, respectively) (table 5).

Women seem to have a greater problem with high cholesterol, although overall levels are considerably lower than in the HSE 2011. Fifteen per cent of Deaf men and $11 \%$ of Deaf women had a total cholesterol to high density lipoprotein ratio (TC/HDL) above 4.5.

The use of HMG CoA reductase inhibitors (statins) among the Deaf participants was associated with lower cholesterol levels (mean $3.80 \mathrm{mmol} / \mathrm{L}$ compared to mean 4.69 with no treatment). However, only $31 \%$ of those who had elevated cholesterol said they had been provided with this treatment. Treatment rates for the general population reported in HSE 2011 seem higher at $79 \%$ for men and $71 \%$ for women.

\section{Diabetes}

The self-reported prevalence of diabetes among Deaf participants was $7 \%$ (7\% males, $6 \%$ for females) This is similar to the HSE 2011 figures for people with doctordiagnosed diabetes (recalculated having removed the oldest age group who do not match the Deaf sample) of $7 \%$ (9\% males, $5 \%$ females). We considered the relationship of self-report of diabetes and the measurement of fasting glucose levels. Overall, $8 \%$ of the Deaf sample had glucose measurements in the prediabetic range, and $3 \%$ were diabetic (table 6 ).

Of those who believed they did not have diabetes, $8 \%$ had elevated blood sugar levels. Of those with raised levels of blood sugar at prediabetic levels, more than three quarters $(77 \%)$ were unaware of it. Of those who reported diabetes, $44 \%$ had normal levels of blood sugar; so nearly $56 \%$ had diabetes which was not under

Table 4 Self-reported cardiovascular disease (CVD) by age (\%) (Deaf $n=288$, HSE $2011 \mathrm{n}=8380)$

\begin{tabular}{lcl}
\hline & $\begin{array}{l}\text { Deaf self-report } \\
\text { CVD }\end{array}$ & $\begin{array}{l}\text { HSE self-report } \\
\text { ('doctor } \\
\text { diagnosed') CVD }\end{array}$ \\
\hline 25-44 years & 1.7 & 5.3 \\
$45-64$ years & 11.5 & 14.1 \\
$65-82$ years & 11.1 & 26.2 \\
\hline
\end{tabular}

Table 5 Distribution (\%) of total cholesterol levels, by gender $(n=274)$

\begin{tabular}{llll}
\hline & $\begin{array}{l}\text { Desirable } \\
\text { cholesterol } \\
(\leq \mathbf{5 m o l} \mathbf{~} \mathbf{)})\end{array}$ & $\begin{array}{l}\text { Elevated } \\
\text { cholesterol } \\
(>\mathbf{5} \mathbf{~ m m o l} / \mathbf{L})\end{array}$ & $\begin{array}{l}\text { HSE 2011 } \\
\text { elevated } \\
\text { cholesterol }\end{array}$ \\
\hline Men & 77.5 & 22.4 & 56 \\
Women & 58.6 & 41.3 & 57 \\
Overall & 67.5 & 32.4 & 57 \\
\hline \multicolumn{2}{l}{ HSE, Health Survey for England. }
\end{tabular}

control-although we note that the actual numbers are small in this subgroup.

Overall, Deaf participants had similar rates of diabetes to the general population, but were less likely to be aware of the problem and more likely to have inadequate control when they have been diagnosed with diabetes.

\section{Respiratory conditions}

The HSE (2010) reported that $16 \%$ of adult men and $17 \%$ of adult women had been diagnosed with asthma at some time in their life. Asthma was self-reported at a similar level among the Deaf participants: $15 \%$ and $17 \%$ for men and women, respectively.

Chronic obstructive pulmonary disease (COPD) appeared to be uncommon in the Deaf population. The self-reported rate from Deaf participants was less than $1 \%$ -for example, only one person mentioned this. In comparison, in the HSE (2010) $4 \%$ of men and $5 \%$ of women had at some time been diagnosed with COPD. This may be a result of low rates of smoking by Deaf adults, but it may also reflect undiagnosed illness, misdiagnosis (eg, 'asthma') or failure to communicate effectively a diagnosis of COPD.

\section{Depression}

Participants were asked if they suffered from 'depression', with no definition supplied. The rates of depression self-reported by Deaf participants were $24 \%$ overall; $32 \%$ women and $14 \%$ men-similar rates to those from other studies of Deaf adults. ${ }^{12}$

Only $15 \%$ of those who reported that they had depression were using antidepressant drugs. In comparison, the QOF figure for treated clinical depression (mixed depression and anxiety) was 12\% in 2011-2012.

\section{Smoking}

The same percentage $(8 \%)$ of men and women reported smoking. This compares to the reported UK rate (2010) of $21 \%$ for men and $20 \%$ for women. ${ }^{13}$ More Deaf women have never smoked (72\%) compared to men $(61 \%)$.

\section{Alcohol consumption}

Participants were asked to define their average weekly consumption of alcohol in units. Average alcohol consumption was self-reported as 5.4 units for men and 3.4 units for women. These figures are very low in comparison to the self-reported mean alcohol consumption for 
Table 6 Self-reported diabetes and measured fasting blood glucose (row \%)

\begin{tabular}{|c|c|c|c|c|}
\hline Self-report & Normal (<6.1 mmol/L) & Prediabetic (6.1-7.0 mmol/l) & Diabetic (>7.0 mmol/L) & $\mathrm{n}=$ \\
\hline No diabetes & 92.4 & 6.8 & 0.8 & 249 \\
\hline Diabetes & 44.4 & 27.8 & 27.8 & 18 \\
\hline Overall & 89.1 & 8.2 & 2.6 & 267 \\
\hline \multicolumn{5}{|l|}{ (Column \%) } \\
\hline Self-report & Normal (<6.1 mmol/L) & Prediabetic (6.1-7.0 mmol/L) & Diabetic (>7.0 mmol/L) & \\
\hline No diabetes & 96.6 & 77.3 & 28.6 & \\
\hline Diabetes & 3.4 & 22.7 & 71.4 & \\
\hline$n=$ & 238 & 22 & 7 & \\
\hline
\end{tabular}

the general UK population of 15.6 units for men and 9.5 units for women. ${ }^{14}$

Our study showed that $33 \%$ of Deaf men and $40 \%$ of Deaf women do not drink at all. If we remove these from the calculation, the weekly consumption among those who do drink is 8.0 units (males) and 5.7 units (females), which is still well below the figures reported for the general population.

\section{DISCUSSION}

\section{Summary of findings}

This study of BSL-using Deaf adults has shown high levels of risk factors for common conditions, such as CVD, hypertension and diabetes, and high levels of selfreported depression but low levels of reported smoking and alcohol consumption. Deaf people had high rates of raised $\mathrm{BP}$ at assessment, which could reflect undetected hypertension and poorly controlled hypertension. Half of Deaf people reporting CVD appeared to not be on appropriate treatment. One-third of Deaf participants had total cholesterol $>5 \mathrm{mmol} / \mathrm{L}$ but treatment rates were half that of the general population rate. Overall, Deaf adults had similar rates of diabetes to the general population, but were less likely to be aware of problems with glucose tolerance and more likely to have inadequate control when they have been diagnosed with diabetes. The prevalence of overweight and obesity was high in Deaf people, especially those over 65 years of age.

\section{Strengths and limitations of this study}

The strengths of the methods used in this study are that BSL was utilised throughout and that as well as collecting questionnaire and interview data, a structured medical assessment was undertaken. By using an independent provider (Bupa Healthcare), we were able to obtain a standardised health assessment on all participants, whether resident in England, Scotland or Wales. The disadvantage of not having access to the participants' own medical records was offset by the advantage of having an independent structured health report on each participant.

There are several caveats which should be considered when interpreting the results. First, we were usually reliant on self-report for the medical history and the medication usage, and did not have access to individuals' health records although some participants did bring their list of prescribed medication. This is also an issue in most health surveys, including HSE. Self-report of medical problems can be associated with bias in both directions-an exaggeration of medical diagnoses (eg, any wheeze is categorised as asthma), or an underreporting of chronic conditions (eg, hypertension, high cholesterol) through lack of awareness, denial or poor communication by the medical practitioner. Second, the medical assessment offered by Bupa, while broadly the same as their routine 'well person' check, was a single check on 1 day and did not include any information from the individual's existing medical record. For example, no serial BP or ambulatory BP measurements were available on participants and no measurements were made of lung function. Third, the data sets were used to provide comparisons with the hearing population have their own limitations. The QOF data are derived only from English general practices. The data are aggregated by practice rather than patient level and cannot be treated as prevalence data. When using the QOF in making any comparison between Deaf and hearing populations, we are effectively treating our sample of Deaf adults as if they all belonged to the same general practice and comparing them as a group to other general practices in England. Although HSE is a large-scale study, it has all the usual problems in response rates and participation. The sample for 2011 was over-represented by women $(56 \%)$ and varied in response (better in the North of England than in London). The overall response rate was $59 \%$ of all those adults eligible to take part, but $39 \%$ proceeded to the nurse interview and only $29 \%$ gave a blood sample.

\section{Reference to existing literature}

Although hypertension cannot be diagnosed on the basis of two BP readings on 1 day, the BP results are of concern as they indicate that Deaf adults are not only at risk of hypertension but also show an apparent lack of awareness of the problem. This lack of awareness of raised BP also occurs, but is less prominent, in the general population. ${ }^{15}$ Owing to difficulties in accessing routine health checks and poor communication in primary care, it is probable that Deaf people have their BP measured less frequently and action is less likely to be taken over 
one-off elevated reading, than among hearing people. Our data also show that even if prescribed antihypertensives, the Deaf patient may not be taking enough tablets or may not be taking the medication regularly to control the BP-again suggesting that communication with doctors and nurses has not been clear. Difficulties in access and communication, and reduced trust with general practice were themes arising from the interviews with Deaf participants, reported in a companion article. ${ }^{16}$

Our results indicated lower rates of self-reported CVD than the general population, but also lower rates of treatment with antiplatelet medication. This could be due to genuine lower rates (associated with less smoking) but could also reflect underdiagnosis. Studies from the $\mathrm{USA}^{17}$ have shown that Deaf people are at a double disadvantage in accessing health information about CVD. Pollard and Barnett ${ }^{18}$ showed that even highly educated Deaf adults scored only at the level of schoolchildren aged 14-15 years for health literacy. The combination of the levels of $\mathrm{BP}$ and the raised risk of serious illness calculated from BMI and waist circumference will potentially reduce life expectancy in the Deaf compared to hearing populations.

The finding that more than half of the Deaf participants diagnosed with diabetes were not adequately controlled is also of concern, as Deaf people are put at risk of preventable complications, including blindness, but in the general population in the UK, the prevalence of inadequate glycaemic control has been generally high $(>60 \%)$ in patients with type 2 diabetes. ${ }^{19}$ Similar to the hearing population, $8 \%$ of Deaf adults had fasting blood sugars in the prediabetic or intermediate hyperglycaemia range. ${ }^{20}$ However, although people with prediabetes are at high risk for diabetes and evidence points to high potential benefit from lifestyle interventions, ${ }^{21}$ diabetes prevention requires societal change and a concerted global public health approach. ${ }^{22}$

There was a high prevalence of obesity in the Deaf sample, particularly in women, and in those over 65 years. We had no reliable data on activity levels in our sample nor details of diet, but it is probable that the overweight and obesity seen in Deaf people is due to the same factors as the general population-for example, a mixture of intake of calories in excess of metabolic requirements and a lack of physical activity. Health promotion messages on healthy eating and regular exercise designed for the hearing population are not reaching the Deaf community, especially the older members of the community (in whom the obesity problem is greatest). The problem of access of the Deaf community to health promotion messages is illustrated by the finding that understanding and knowledge of AIDS and risk behaviours were found to be lower in deaf and hard-of-hearing people than in hearing people. ${ }^{23}$ In addition to living in the same obesogenic environment as hearing people, Deaf adults also face barriers due to communication difficulties and stigma in participating in sporting activities, and in joining gyms, clubs and slimming groups.
In contrast, the Deaf community seems to have taken note of the health promotion messages about smoking, maybe because of prominent visual warnings on cigarette packaging, and this was associated with lower rates of self-reported chronic respiratory disease and CVD. The self-reported alcohol consumption was also lower than the general population, which may partially be due to communication issues in BSL, but also probably reflects different social patterns of drinking and a relatively high rate of abstinence in the Deaf community.

\section{CONCLUSION}

Deaf adults in the UK have high rates of known risk factors for chronic disease, such as CVD, hypertension and diabetes, and high rates of self-reported depression. Lack of awareness, underdiagnosis and undertreatment of chronic conditions may be putting them at risk of preventable illhealth and potentially reduced life expectancy.

\section{Author affiliations}

${ }^{1}$ School of Social and Community Medicine, University of Bristol, Bristol, UK ${ }^{2}$ Deaf Studies Trust, The Vassall Centre, Bristol, UK

${ }^{3}$ SignHealth, Beaconsfield, Buckinghamshire, UK

${ }^{4}$ Deaf Studies, University of Bristol, Bristol, UK

Acknowledgements The authors wish to thank the study participants, support workers and interpreters, and Bupa Healthcare for their collaboration.

Contributors AE contributed to study design, was a member of the study management committee, supervised training, data collection and analysis and contributed to data interpretation. He wrote the first draft of the paper and approved the final version of the manuscript. MR contributed to study design, was a member of the study management committee, and contributed to data interpretation. He contributed to earlier drafts and approved the final version of the manuscript. HS was one of the study researchers and a member of the study management committee. She enrolled participants, collected outcome data, prepared data files for analysis and contributed to data interpretation. She approved the final version of the manuscript. LA was one of the study researchers and a member of the study management committee. She enrolled participants, collected outcome data, prepared data files for analysis and contributed to data interpretation. She approved the final version of the manuscript. AA was an expert member of the study management committee. He contributed to trial design, data interpretation, earlier drafts of the manuscript and approved the final version of the manuscript. JK was the PI on the study. He contributed to study design, chaired the study management committee, supervised data collection, undertook most of the analysis and contributed to data interpretation. He wrote the report to funders, contributed to earlier drafts of the manuscript and approved the final version of the manuscript.

Funding This research was funded by the Big Lottery Fund. All authors are independent of the funders.

\section{Competing interests None.}

Ethics approval Ethical approval for the study was given by the NHS Local Research Committee (NRES Committee South West-Frenchay. ref no: 11/sw/ 0151).

Provenance and peer review Not commissioned; externally peer reviewed.

Data sharing statement Alan Emond can be contacted regarding access to the data set.

Open Access This is an Open Access article distributed in accordance with the Creative Commons Attribution Non Commercial (CC BY-NC 4.0) license, which permits others to distribute, remix, adapt, build upon this work noncommercially, and license their derivative works on different terms, provided the original work is properly cited and the use is non-commercial. See: http:// creativecommons.org/licenses/by-nc/4.0/ 


\section{REFERENCES}

1. Kyle JG, Woll B. Sign language. Cambridge: Cambridge University Press, 1985.

2. ONS. UK census 2011. http://www.ons.gov.uk/ons/guide-method/ census/2011/

3. RNID. A simple cure. 2004. http://www.stah.org/Portals/0/docs/RNID $\% 20 A \% 20$ Simple\%20Cure.pdf survey

4. Kyle J, Reilly AM, Allsop L, et al. Investigation of Access to Public Services in BSL. Edinburgh: Scottish Executive Social Research, 2005. http://www.scotland.gov.uk/Resource/Doc/930/ 0012107.pdf

5. Alexander A, Ladd P, Powell S. Deafness might damage your health. Lancet 2012;379:979-81.

6. Barnett S, McKee M, Smith SR, et al. Deaf sign language users, health inequities, and public health: opportunity for social justice. Prev Chronic Dis 2011;8:1-6.

7. Fellinger J, Holzinger D, Pollard R. Mental health of deaf people. Lancet 2012;379:1037-44.

8. SignHealth. Research into the health of deaf people. 2013. http:// www.signhealth.org.uk/deaf-health-report-stage-one/

9. Health Survey for England 2011 (HSE). http://www.noo.org.uk/data sources/adult/health survey for england

10. Quality Outcomes Framework 2012 (QoF). http://qof.hscic.gov.uk/

11. NICE guidance on obesity management 2006. http://guidance.nice. org.uk/CG43

12. Kvam MH, Loeb M. Mental health in deaf adults: symptoms of anxiety and depression among hearing and deaf individuals. J Deaf Stud Deaf Educ 2007;12:1-7.
13. UK smoking rates 2010. http://www.cancerresearchuk.org/ cancer-info/cancerstats/types/lung/smoking/\#percent

14. ONS. Drinking: adults' behaviour and knowledge in 2009. London: The Office for National Statistics, 2010.

15. Smith WCS, Lee AJ, Crombie IK, et al. Control of blood pressure in Scotland: the rule of halves. Br Med J 1990;300:981-3.

16. Emond A, Ridd M, Sutherland $\mathrm{H}$, et al. Access to primary care affects the health of Deaf people. Brit J Gen Pract, February 2015:95-6.

17. Margellos-Anast H, Estarziau M, Kaufman G. Cardiovascular disease knowledge among culturally Deaf patients in Chicago. Prev Med 2006;42:235-9.

18. Pollard RQ, Barnett S. Health-related vocabulary knowledge among deaf adults. Rehabil Psychol 2009;54:182-5.

19. Fox KM, Gerber RA, Bolinder B, et al. Prevalence of inadequate glycemic control among patients with type 2 diabetes in the United Kingdom general practice research database: a series of retrospective analyses of data from 1998 through 2002. Clin Therap 2006;28:388-95

20. World Health Organization. Definition and diagnosis of diabetes mellitus and intermediate hyperglycemia: report of a WHO/IDF consultation. WHO, 2006.

21. Vegt F, Dekker JM, Jager A, et al. Relation of impaired fasting and postload glucose with incident type 2 diabetes in a Dutch population: the Hoorn study. JAMA 2001;285:2109-13.

22. Judkin JS, Montori VM. The epidemic of pre-diabetes: the medicine and the politics. BMJ 2014;349:4485.

23. Woodroffe T, Gorenflo DW, Meador HE, et al. Knowledge and attitudes about AIDS among deaf and hard of hearing persons. AIDS Care 1998;10:377-86. 